\title{
From the Outside in: Burnout as an Organizational Issue
}

\author{
Jay Coakley \\ Independent Scholar
}

Most of us know the parable of the blind men and the elephant: Depending on the version of the story, there were 3-8 blind men who encountered an elephant. One approached the elephant's leg and concluded that the elephant was like a tall tree; another encountered its trunk and concluded that it resembled a snake; and the third approached it from behind, grasped the tail, and said it was similar to a rope. When the men were asked to present their conclusions, each used the evidence he'd gathered, and presented definitive but radically divergent conclusions about the reality of the elephant.

According to one version of this story, each of the men insisted that his conclusion represented the truth about elephants and dismissed the conclusions of the others. Eventually they came to blows over whose truth would go on the record as THE truth.

In another version of the story, the raja who arranged this scenario and introduced the elephant to the men took great pleasure in their conflict because it confirmed his argument that scholars often studied reality from different vantage points and then insisted that only their conclusions were accurate and objective. The raja knew that all observations were incomplete and that the production of knowledge ultimately required that scholars come together to synthesize their research and conclusions to create a fuller, more meaningful understandings of reality.

As I think of the discussions of burnout in this issue of JIS, I imagine that Maureen Weiss, who brought Gould and Whitley, Cureton, and me together, is the raja who wants us to discuss the elephant of burnout in college sports. But I'm quite certain that none of us claims to possess the truth about burnout generally, or burnout among college athletes. So it's unlikely that we'll come to blows. In fact, each of us is here because we're willing to listen and learn with those who have different perspectives and vantage points than we do. My hope is that we'll work to synthesize various perspectives on burnout and create a fuller and more meaningful understanding of it.

Gould and Whitley provide a useful overview of the research and theory on burnout among athletes ranging in age from early adolescence though young adulthood. Nearly all these studies and the theories used to guide them are

The author is an independent scholar and lives in Ft. Collins, CO. 
grounded in psychological approaches, and they approach and analyze burnout from the inside out-in terms of the emotional states, cognitive processes, and attributes of individuals. Their focus, therefore, is on various dimensions and correlates of stress and its impact on the motivation and performance of individual athletes, although training load is an external factor they consider.

I don't take issue with this research or the knowledge it has produced. In fact, it provides important information about the elephant of burnout. But our raja (Maureen Weiss) invited me to this session because she knows that I view burnout from a sociological rather than a psychological or physiological perspective.

I understand that burnout happens to individuals and is embodied and experienced in ways that have both psychological and physiological manifestations and correlates. But as a sociologist my view is that burnout always is situated - that is, it occurs in particular situations and social contexts. Therefore, when I review research on burnout, I'm especially aware of what it might tell us about the social contexts in which burnout among athletes is more or less likely.

These contexts are multilayered-much like a robin's nest-and they consist of cultural values and norms intertwined with ideas, beliefs, rituals, taken-forgranted social arrangements, and observable patterns of organization that people create as they interact with each other. We can view these social creations from various levels that encompass an entire society or a particular type of relationshipwith everything in between: cultural and social regions, communities, crowds, organizations, athletic departments, small groups, athletic teams, and families.

At all levels, these contexts consist of social relationships through which all of us, including college athletes, give meaning to what we do and develop our ideas and beliefs about who we are and how we're connected with the various social worlds in which our experiences occur.

Unfortunately, there is little research focusing on the social contexts in which burnout occurs, and we know little about this side of the elephant. The reasons for this are many, but mainly it's been difficult to gain access to and gather data needed to understand the social contexts in which athletes train and compete-contexts that are likely to influence rates of burnout in sports.

The people who control access to those contexts usually see sociological research as disruptive and misdirected. If they support research at all, they favor studies of individual athletes. For them it makes sense to identify the strengths and weaknesses of individual athletes and then create personalized strategies, such as stress management, to help athletes deal more effectively with the conditions and demands of their sport. Less likely to make sense to them is research that analyzes the organizational contexts in which they coach, manage, and administer sports. This isn't surprising because they've often created those contexts to match their conceptions of reality, and they've usually framed them around authority structures in which they have power to control athletes who are clearly subordinate to them.

Therefore, these gatekeepers prefer researchers who will identify the problems of individual athletes and then provide individualized strategies and interventions that are likely to improve an athlete's performance and enhance the status and record of a coach or administrator. But if researchers can't show that they improve performance — or worse, if they identify problems in the organization and power relations that constitute a team, athletic department, league, or sport gov- 
erning body, the coaches and administrators become justifiably resistant. They're not eager to be criticized, especially by an assumed ivory tower academic person, and they're wary of any evidence calling for alterations of the very structures that legitimize their status and power. This goes for everyone from parents and coaches to athletic directors, sport managers, and executives in sport organizations. These people prefer a view of the elephant that focuses on the attributes of individual athletes and leads to recommendations for closer monitoring - a strategy that further legitimizes and increases their control over athletes and the conditions under which athletes train and compete.

In light of the power relations in college sports, I have questions about the ways that people may apply the findings outlined in the overview of burnout presented by Gould and Whitley. On the one hand, those finding could be used to keep athletes in their sports and maximize their performance potential. Burnout undermines performance; therefore, it's valuable to know the indicators of burnout and the personal coping strategies that may enable an athlete to effectively cope with it without subverting his or her sport performance.

On the other hand, knowledge about burnout could be used to enhance overall developmental opportunities for young people who play sports. Burnout undermines a young person's zest for sport and life in general, therefore, knowledge of the indicators of burnout is valuable because it can lead to interventions that enable the athlete to critically examine the role of sport in his or her life and make informed decisions about sport participation, training, and goals.

This is an important distinction, even though these applications of knowledge are not always mutually exclusive. It's important because researchers who study burnout with the goal of boosting performance are much more likely to obtain funding as well as permissions from gatekeepers to collect and analyze data. This may then lead some researchers to uncritically assume that if they help an athlete remain on the field and performing well, they're also contributing to the athlete's overall development. However, there's considerable evidence showing that playing sports does not automatically lead to positive developmental outcomes (Coakley, 2007; Donnelly, 2007; Fullinwider, 2006; Hartmann, 2003, 2008; Holt, 2007), and that revising expectations for performance, training, and participation itself is often a developmentally wise thing to do, even if it involves the termination of participation in a sport. But many coaches and athletic directors are not inclined to think this way.

Gould and Whitley cite research suggesting that "it takes 10 years or 10,000 hours of deliberate practice to develop one's talent to the level of 'expert' in any field, including that of athletics." The " 10,000 hour rule" was recently popularized by Malcolm Gladwell (2008) who used it as a focal point in his best selling book, Outliers: The Story of Success. Gladwell reviewed the research on excellence and concluded that superstars are neither self-made nor propelled to stardom by their inborn genius. Instead, they invariably benefit from unseen advantages, special opportunities, and cultural legacies that come together to form a context in which they can learn and work in ways that enable them to view and interpret the world as others are unlikely to do. People who reach the top of their fields, from Mozart to Bill Gates, do so because of the advantages, opportunities, and guidance they enjoy, some of which they deserve or earn, and some of which they enjoy due to luck and coincidence. For example, 5-year-old boys born in January have an 
advantage in ice hockey because they are slightly older than their peers in youth hockey leagues, and ultimately they are vastly overrepresented in the NHL. In other words, contexts have an important impact on talent development and the achievement of success.

Advantages, opportunities, and luck are necessary but not sufficient causes of success. Passion and hard work-including at least 10,000 hours of deliberate and focused practice - constitute the other necessary elements of talent development and success (Côté, Baker, and Abernathy, 2007; Ericsson, Prietula, and Cokely, 2007; Morris, 2008). With a few exceptions, research shows this to be the case across a wide variety of fields such as nursing, surgery, classical piano and other musical disciplines, ballet, acting, chess, tennis, swimming, gymnastics, golf, darts, writing, computer programming, aviation, firefighting, and many others.

As Gould and Whitley imply, 10,000 hours of deliberate practice would seem to be a recipe for burnout. Therefore, I've turned to the research on talent development to identify contextual factors that may prevent people from burning out as they work to become one of the best in their fields (Bloom, 1985; Ericsson, 2003, 2006, 2007; Ericsson, Prietula, and Cokely, 2007; Gladwell, 2008; Morris, 2008). This research shows that standouts in most fields, including sports, work remarkably hard. In the majority of cases, they work hard because they have a deep passion for what they do, and the seeds of that passion usually are planted and nurtured during childhood in contexts where children have the opportunity, freedom, and support to explore many activities and play whatever is fun for them (Côté, Baker, and Abernathy, 2007; Fraser-Thomas \& Côté, 2006; Wall and Côté, 2007). Passion doesn't originate in highly structured, adult-controlled activities that demand early specialization and commitments to long term achievement goals. Nor is it nurtured by pep talks about hard work and lectures on the need to concentrate, practice, and be serious. Passion grows out of experiences characterized by play, personal expression, and joy. As it grows, it provides young people with a foundation for emotionally connecting with an activity, claiming it as one's own, and then choosing to develop the skills that enable a person to continually alter and expand experience in ways that preserve "ownership" and excitement.

This process usually occurs before and through the early teens, and when it does, young people in their midteens are ready to specialize in and make commitments to talent development in a particular discipline, activity, or sport. At this point, passion, based on a foundation of enjoyable experiences and emotional connection with a sport, can be merged with specialized practice and skill development leading to pride and personal satisfaction.

During the late-teens and early adulthood, mastery becomes the primary focus in the young person's emerging quest to become an elite performer. Simply being competent is no longer good enough; the goal is to be one of the best. By this time, identity is firmly grounded in one's talent. Research indicates that intensive and deliberate practice guided by expert coaches or mentors leads to the internalization of skills and the formation of an "inner coach," which is a source of critical self-assessments along with strategies for improvement. Lines between joy, creativity, and work are blurred; pleasure now comes with mastering techniques, combining them in creative ways, and meeting high self-expectations. Motivation is primarily intrinsic, even though participation in the activity has become serious and highly focused. 
Two recent studies support this conception of talent development and the achievement of success. One focused on the passion or drive that sustains talent development among young people seeking excellence in classical music and artistic gymnastics (MacArthur, 2008); the other focused on burnout among Gaelic football players in Northern Ireland (Hughes, 2008).

In the first study, only four of eight classical musicians and one of six elite gymnasts continued their participation into young adulthood. The five young people who continued their training each sustained passion by integrating elements of creativity into training and competition. The musicians composed and performed their own music and the gymnast switched from international competition to a college program in which she was allowed to choreograph her routines and determine much of her training regimen. Thus, there was space in their training to add subjectivity to their participation and further to claim the activity as their own.

The second study reported that burnout rates among Gaelic football players were linked with highly autocratic and vertically organized sport and team structures that precluded autonomy and creativity. Burnout and early retirement was common and generally associated with feelings of entrapment and forms of dependency that players claimed were created by rigid control systems enforced by coaches and the governing body of their sport.

Research on talent development and the achievement of success doesn't deal directly with burnout, but it helps us identify contextual factors that are likely to influence burnout rates. On the basis of this research I would hypothesize that burnout is least likely under the following conditions:

1. When children have a history of playing multiple sports informally under conditions allowing them to define sports in their own terms and develop skills and face challenges at their own pace.

2. When specialization is the result of an adolescent's informed choices about priorities and commitments.

3. When involvement in deliberate practice occurs after young people have had sufficient experiences in "deliberate play."

4. When sport programs for adolescent athletes are organized so that young people can accomplish developmental tasks related to identity development at the same time that they train and compete.

5. When parents and coaches strategically nurture the passion and the ownership claims that fuel deliberate practice.

6. When programs and teams are organized to foster the development of an effective inner coach among athletes.

7. When teams and programs are organized to allow athletes to be creative in their training, skill development, and displays of competence.

8. When coaches teach and enable athletes to use their sports as contexts for expanding their experiences, relationships, and identities beyond the realm of sport participation.

9. When coaches empower athletes by guiding and encouraging them to make informed choices in and out of sports. 
10. When sports and sport teams are organized so that athletes control major training decisions and are respected and treated as young adults rather than "kids."

Overall, I agree heartily with Gould and Whitley's recommendation that there be education about burnout-related matters for coaches, support staff, parents, and athletes. At the same time there needs to be more reciprocity in relationships between athletes and others in sport organizations. For example, there should be institutionalized processes through which athletes can assess and even "monitor" their coaches, the organization of the team, and the athletic department in light of their educational and developmental interests.

Burnout is not only an issue in sports; it occurs in many spheres of life. Therefore, such educational programs and assessment processes prepare young people to control their lives in ways that minimize the likelihood of burnout in other spheres of their lives and in the organizations that they manage or influence.

In the meantime, those of us who do research should do a better job of studying and producing knowledge about the whole elephant. At this point, we're not able to accurately predict success or burnout, so it is important to gather retrospective data about the experiences of young people who represent examples of both. These papers illustrate that burnout is multidimensional in terms of causes, dynamics, and consequences. Of course, this kind of complexity muddies methodological and theoretical waters, but it lends more reality to our efforts to develop realistic and effective interventions and policies.

\section{References}

Bloom, B. (1985). Developing talent in young people. New York, NY: Random House.

Coakley, J. (2007). Socialization and sports. In G. Ritzer (Ed.), Encyclopedia of sociology (pp. 4576-4580). London, New York: Blackwell.

Côté, J., Baker, J.,and Abernathy, B. (2007). Practice and play in the development of sport expertise. In R. Eklund and G. Tenenbaum (Eds.), Handbook of sport psychology (3rd ed; pp. 184-202). Hoboken, NJ: Wiley.

Donnelly, P. (with Simon Darnell, Sandy Wells, and Jay Coakley). (2007). The use of sport to foster child and youth development and education. In Sport for Development and Peace, International Working Group (SDP/IWG), Literature Reviews on Sport for Development and Peace (pp. 7-47). Toronto, Ontario: University of Toronto, Faculty of Physical Education and health. Online: http://iwg.sportanddev.org/data/htmleditor/ file/Lit.\%20Reviews/literature\%20review\%20SDP.pdf (retrieved 9/10/08).

Ericsson, K.A. (2003). The acquisition of expert performance as problem solving: Construction and modification of mediating mechanisms through deliberate practice. In J. E. Davidson and R. J. Sternberg (Eds.), Problem solving (pp. 31-83). New York: Cambridge University Press.

Ericsson, K.A. (2006). The influence of experience and deliberate practice on the development of superior expert performance. In K.A. Ericsson, N. Charness, P. Feltovich, and R.R. Hoffman (Eds.), Cambridge handbook of expertise and expert performance (pp. 685-706). Cambridge, UK: Cambridge University Press.

Ericsson, K.A. (2007). Deliberate practice and the modifiability of body and mind: Toward a science of the structure and acquisition of expert and elite performance. International Journal of Sport Psychology, 38, 4-34. 
Ericsson, K.A., Prietula, M.J., and Cokely, E.T. (2007). The making of an expert. Harvard Business Review 85 (7/8; July-August): 114-121; online, http://harvardbusinessonline.hbsp.harvard.edu/hbsp/hbr/articles/article.jsp

Fraser-Thomas, J., \& Côté, J. (2006). Youth sports: Implementing findings and moving forward with research. Athletic Insight: The Online Journal of Sport Psychology 8, 3: online, http://www.athleticinsight.com/Vol8Iss3/YouthSports.htm (retrieved 2/1/09)

Fullinwider, R.K. (2006). Sports, youth and character: A critical survey. CIRCLE WORKING PAPER 44, The Center for Information and Research on Civic Learning and Engagement. College Park, MD: University of Maryland.

Gladwell, M. (2008). Outliers: The story of success. New York: Little, Brown and Company.

Hartmann, D. (2003). Theorizing sport as social intervention: A view from the grassroots. Quest, 55(2), 118-140.

Hartmann, D. (2008). High school sports participation and educational attainment: Recognizing, assessing, and utilizing the relationship. Report to the LA84 Foundation. Online: http://www.la84foundation.org/3ce/HighSchoolSportsParticipation.pdf.

Holt, N.L. (Ed.). (2007). Positive youth development through sport. Milton Park/New York: Routledge.

Hughes, L. (2008). Wearing their chains willingly: Hegemony, subordination, and athlete burnout. Paper presented at the annual conference of the North American Society for the Sociology of Sport, Denver (November 5-8).

MacArthur, L. (2008). The drive to strive: Exploring the experiences of elite-level adolescent artistic performers. Dissertation in the Department of Curriculum, Teaching, and Learning; Ontario Institute for Studies in Education of the University of Toronto.

Morris, C. (2008). Hard work tops talent ... especially when talent doesn't work hard. Online, http://www.igs.net/ cmorris/book_review_tchoeaep_june_17_2008.htm (retrieved $1 / 31 / 09)$

Wall, M., \& Côté, J. (2007). Developmental activities that lead to dropout and investment in sport. Physical Education and Sport Pedagogy, 12(1), 77-87. 